\title{
Bronchial epithelium in children: a key player in asthma
}

\author{
Ania Carsin ${ }^{1,2}$, Julie Mazenq ${ }^{1,2}$, Alexandra Ilstad ${ }^{2}$, Jean-Christophe Dubus ${ }^{3}$, \\ Pascal Chanez ${ }^{2,4}$ and Delphine Gras ${ }^{2}$
}

\begin{abstract}
Affiliations: ${ }^{1}$ Unité de Pneumologie Pédiatrique, hôpital Timone-Enfants, Assistance Publique Hopitaux de Marseille, Marseille, France. ${ }^{2}$ UMR Inserm U1067 CNRS 7333, Aix Marseille University, Marseille, France. ${ }^{3}$ CNRS, URMITE 6236, CHU Timone-Enfants, Aix-Marseille Université, Unité de pneumologie et médecine infantile, Marseille, France. ${ }^{4}$ Clinique des bronches, Allergie et Sommeil, Hôpital Nord, Assistance Publique Hopitaux de Marseille, Marseille, France.
\end{abstract}

Correspondence: Ania Carsin, CHU Timone-Enfants, Assistance Publique Hopitaux de Marseille, 264, rue Saint Pierre, 13385 Marseille Cedex 5, France. E-mail: ania.carsindap-hm.fr

ABSTRACT Bronchial epithelium is a key element of the respiratory airways. It constitutes the interface between the environment and the host. It is a physical barrier with many chemical and immunological properties. The bronchial epithelium is abnormal in asthma, even in children. It represents a key component promoting airway inflammation and remodelling that can lead to chronic symptoms. In this review, we present an overview of bronchial epithelium and how to study it, with a specific focus on children. We report physical, chemical and immunological properties from ex vivo and in vitro studies. The responses to various deleterious agents, such as viruses or allergens, may lead to persistent abnormalities orchestrated by bronchial epithelial cells. As epithelium dysfunctions occur early in asthma, reprogramming the epithelium may represent an ambitious goal to induce asthma remission in children.

0 @ERSpublications

Bronchial epithelium is a morphological and functional dysregulated gatekeeper in asthmatic children http://ow.ly/Y4MaM

\section{Introduction}

Chronic inflammatory respiratory diseases represent a major health problem worldwide. Asthma affects $7-10 \%$ of children and the number of new patients is still growing [1]. Our current understanding, despite recent improvements, of the cellular and molecular mechanisms governing the pathogenesis of this disease is often incomplete. Asthma results from a combination of genetic susceptibility including epigenetic mechanisms and a deleterious environment. The airway epithelium is a potentially important and attractive target to better understand the disease and hopefully identify new therapeutics. Indeed, the airway epithelium is at the interface between the host and the inhaled environment. It is an efficient physical barrier, but also represents the first line of defence against microorganisms, airborne irritants and allergens [2].

In adults, the role of the bronchial epithelium in asthma is being deciphered thanks to numerous recent in vitro studies using animal models and samples derived from living asthmatic patients. Bronchial epithelium has recently been established as a crucial partner participating in the genesis of asthma. In fact, it leads to exacerbations and is in part responsible for the chronicity and severity of the disease. The epithelium orchestrates and influences adaptive immune responses and functions as an interface between innate and adaptive immune regulation [3]. Cohort clinical studies suggest asthma severity has an early onset. Loss of lung function seems to occur very early in childhood $[4,5]$, which underlies the necessity of studying epithelium in asthmatic children.

Received: Dec 192015 | Accepted after revision: Jan 242016

Conflict of interest: Disclosures can be found alongside the online version of this article at err.ersjournals.com

Provenance: Submitted article, peer reviewed.

Copyright OERS 2016. ERR articles are open access and distributed under the terms of the Creative Commons Attribution Non-Commercial Licence 4.0. 
However, few studies have investigated the putative role of the bronchial epithelium in asthmatic children. The purpose of this review is to focus on current knowledge of the bronchial epithelium in children, particularly in relation to asthma. Epithelium in the context of cystic fibrosis will not be described.

\section{How to study the bronchial epithelium?}

\section{Animal models}

Most of the data regarding bronchial epithelium in health and diseases has been generated using animal models, notably mouse models, due to the availability of gene targeted and transgenic animals. These models are used to study the impact of structural and functional airway epithelium changes. They have been shown to be useful in short-term models of chronic airway diseases [6]. In asthma, most of the rodent models require pre-sensitisation and reflect the allergen-induced acute situation [7]. However, the bronchial epithelium of rodents and humans are not the same and several differences have been widely reported such as the thickness or the complexity of the tissue. There also are major differences in the epithelial cell population, with mucus cells and basal cells predominating in primates and club cells being the principal nonciliated cell population in mice [8].

Horses naturally develop an asthma-like condition, currently known as "heaves", that affects 10-15\% of mature horses [9]. Heaves shares remarkable similarities to human asthma with respiratory exacerbations comparable to those affecting severe asthma patients. Therefore, horses are the only natural animal model of asthma. However, horses develop heaves in adulthood and cannot be used as an asthma model in children. These facts encourage studies using human samples in order to better characterise the bronchial epithelium in health and disease, particularly in children with asthma.

\section{Human samples}

The study of bronchial epithelium requires access to the tissue. In most cases, this access necessitates invasive techniques such as bronchial fibre-optic bronchoscopy. This approach needs ethics approval and authorisations are difficult to obtain especially when they involve children.

Bronchial epithelial tissue can be extracted from different samples. Lung donor explants [10] can be obtained at autopsy or after surgery. Endobronchial biopsies and bronchial brushings are obtained using fibre-optic bronchoscopy or using a blind non-bronchoscopic technique through a tracheal tube [11].

Bronchial explants can be obtained and considered as nonpathological tissue during lobectomy for distal lung malformation in children. Moreover, during the lung transplantation process, bronchial explants can be dissected from the lung donor. In most samples obtained from autopsies, cause of death and medical history, including smoking and duration of mechanical ventilation, are crucial factors to be able to rely on the results seen in vitro. Unfortunately, this information is usually scarce. Bronchial explants can easily provide a reasonable number of airway epithelial cells using enzymatic dissociation $[12,13]$.

Bronchial brushing [11, 14-17] is performed during fibre-optic bronchoscopy or using a blinded non-bronchoscopic technique through an endotracheal tube or a portable bronchoscope directed technique through a laryngeal mask. It is a safe, quick and potentially valuable technique to obtain bronchial epithelial cells [11]. Some teams have obtained ethical approval to recruit children admitted to the hospital for routine surgery (ear, nose and throat procedures such as adenotonsillectomy) and to obtain epithelial samples during induction of anaesthesia. The advantage of this approach is that it allows many samples to be obtained with a well-tolerated technique. The limitations are obviously represented by the severity of the disease, since most of the subjects investigated here are usually normal, allergic non-asthmatic or mildly allergic asthmatic children, and by the number and origin of the brushed cells.

Endobronchial biopsies are commonly used to assess pathology and study the morphological features of bronchi [18]. Endobronchial biopsies not only allow the description of the bronchial epithelium but also of the submucosa, including infiltration of resident and recruited inflammatory cells and other structural cells, such as smooth muscle cells, nerves and fibroblasts. For this purpose, endobronchial biopsies are frozen or embedded in paraffin or resins such as glycol methacrylate. Biopsies can be stained using various conventional staining techniques such as haematoxylin-eosin, Periodic acid-Schiff for mucin identification, Trichrome Masson for reticular basement membrane (RBM) study or immunohistochemistry using specific antibodies (figure 1). Examination of endobronchial biopsies permits an overview of the tissue at aiven moment. However, all structures are not always present and the investigation of cellular and molecular aspects of the bronchial epithelium is limited. RNA can be extracted and analysed using a single gene or a transcriptomic approach from endobronchial biopsies fixed in RNAlater solution (Qiagen, Les Ulis, France). This does not allow for discrimination between genes from cells of epithelial origin and genes derived from other inflammatory or structural cells. From the initial endobronchial biopsies, epithelial cell 

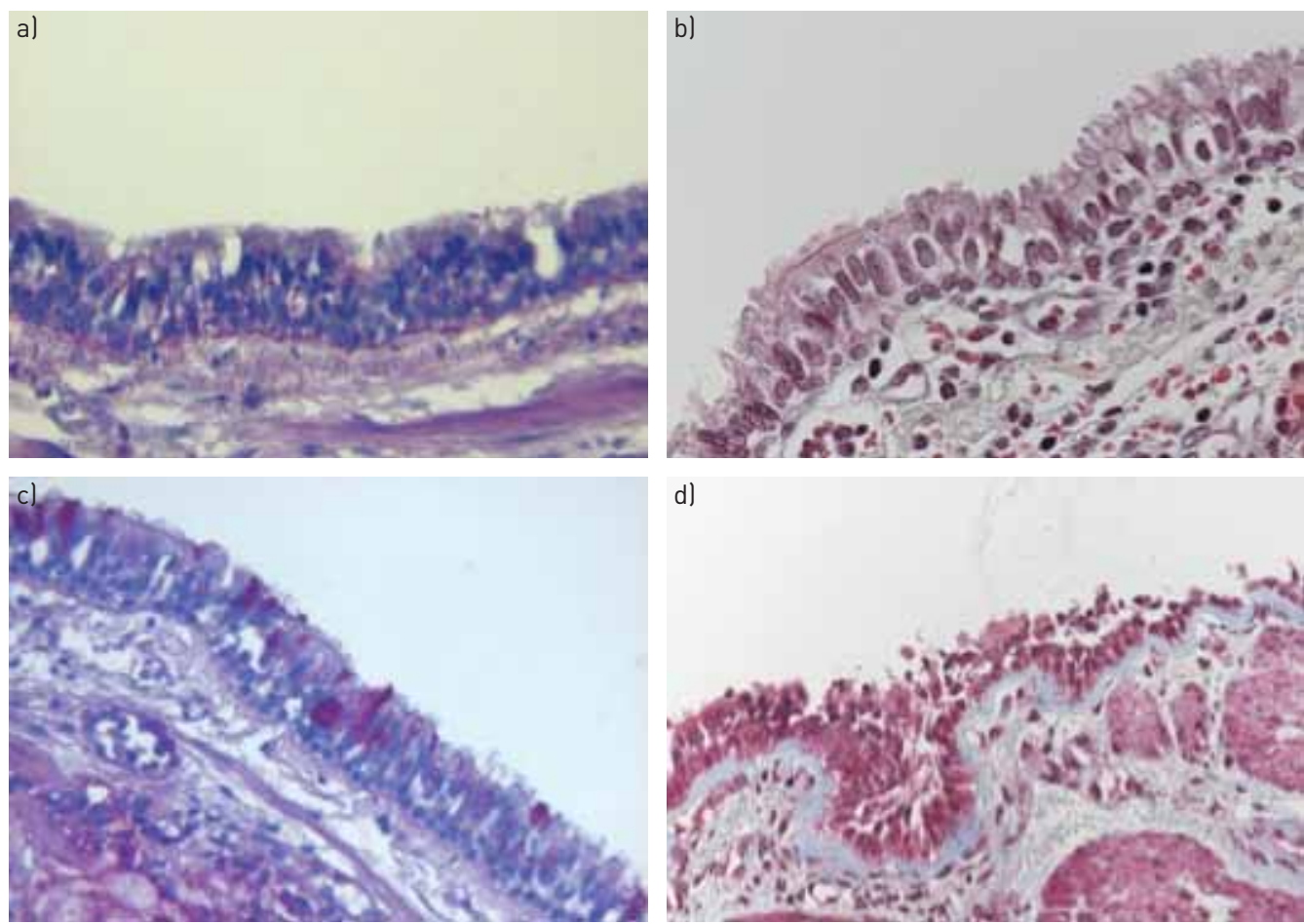

FIGURE 1 Bronchial epithelium obtained from a, b) healthy children and c, d) asthmatic children after a, c) Periodic acid-Schiff staining and b, d) Trichrome Masson staining.

culture can be performed in vitro. This allows specific functional investigation of the bronchial epithelium. Unfortunately, the samples obtained are small, even more so in children.

The nasal epithelium is also an option for studying respiratory tract mucosa. Indeed, the upper and lower airways are united in health and disease by epidemiological, anatomical, physiological, immunopathological and pharmacological factors. This led to the hypothesis for united airways disease [19]. Nasal epithelium is easier to collect especially using brushings, which enable collection of iterative samples.

Mediators released by bronchial epithelial cells, such as cytokines and chemokines, could be studied by bronchoalveolar lavage (BAL); however, this technique does not allow bronchial epithelial cells to be obtained.

The limitations and benefits of the different sampling techniques are summarised in table 1.

TABLE 1 The limitations and benefits of different sampling techniques used to obtain bronchial epithelial cells

\begin{tabular}{|c|c|c|}
\hline Methods & Limitations & Benefits \\
\hline \multirow[t]{3}{*}{ Tissues obtained from autopsy } & Fatal asthma & Bronchi to alveoli \\
\hline & No reliable clinical data & Whole lung studied \\
\hline & No scalable data & $\begin{array}{l}\text { Most serious forms of } \\
\text { asthma studied }\end{array}$ \\
\hline \multirow[t]{3}{*}{ Endobronchial biopsies } & Small size & Invasive \\
\hline & $\begin{array}{l}\text { No reproducibility of the } \\
\text { biopsied areas }\end{array}$ & $\begin{array}{l}\text { Inflammation and associated } \\
\text { structural abnormalities }\end{array}$ \\
\hline & Proximal bronchi & \\
\hline \multirow[t]{2}{*}{ Endobronchial brush } & No tissue sample & Less invasive \\
\hline & & Can be done without an endoscopy \\
\hline Nasal biopsies/brush & Upper airway & Easy to collect \\
\hline \multirow{3}{*}{ Bronchoalveolar lavage } & Distal bronchi & Inflammatory markers \\
\hline & No tissue sample & Invasive \\
\hline & $\begin{array}{l}\text { Few validated markers } \\
\text { of remodelling }\end{array}$ & \\
\hline
\end{tabular}




\section{Culture of bronchial epithelial cells}

Bronchial epithelial cells can be cultured from a number of different initial samples: bronchial explants, endobronchial biopsies and bronchial brushings. Ex vivo culture of primary epithelial cells is well established. It begins with a dedifferentiation period, then using an air-liquid interface culture allows a 21-28 day period for production of fully differentiated pseudostratified bronchial epithelium similar to the epithelium observed on the initial endobronchial biopsies (figure 2) [10]. These culture systems can also mimic cellular crosstalk through the air-blood barrier when co-culturing bronchial epithelial cells with inflammatory cells such as mast cells [20], fibroblasts [21] and macrophages [22]. The culture of bronchial epithelial cells allows the differentiation process in health and disease to be understood. Cells can be exposed to various stimulants such as microorganisms, pollutants or allergens. The sampling of culture supernatant or medium from the basolateral compartment makes it possible to measure epithelial derived mediators. Alternatively, cells can be detached and investigated for protein, RNA and DNA content. In addition, the morphology of the cells can be observed using confocal or ultrastructural microscopy.

In children, the release of mediators from bronchial epithelial cells and nasal cells under the same conditions has been compared in order to enable use of nasal epithelium instead of bronchial epithelium. Nasal and bronchial epithelia have an identical morphological appearance on optical microscopy [23]. The responses of nasal and bronchial epithelia to cytokine stimulation (interleukin (IL)- $\beta$ and tumour necrosis factor- $\alpha$ ) were also similar [23]. Indeed, IL-8, IL-6, RANTES and matrix metalloproteinase- 9 were secreted in an identical manner by nasal and bronchial epithelial cells. These results are controversial, however, as other authors report that cells from nasal origins have different functional properties when compared with bronchial epithelial cells from children [24]. Therefore, nasal epithelial cells would not reflect activation of bronchial cells strengthening the need to obtain bronchial epithelial cells.

\section{Lung development}

The bronchial epithelium appears early in lung organogenesis. Lung respiratory epithelium originates from the endoderm. The earliest developmental stage is the pseudoglandular stage (5-17 weeks of pregnancy) [25]. Epithelial tubes lined with cuboidal epithelial cells go through branching morphogenesis and look like an exocrine gland. However, this structure is too immature to support efficient gas exchange. During the canalicular stage (16-25 weeks of pregnancy) the number of capillaries increases, respiratory bronchioles and alveolar ducts form, and the airway epithelium differentiates into peripheral pneumocytes and proximal cuboidal cells. The terminal saccular stage ( 24 weeks to late fetal period) allows the differentiation of alveolar epithelial cells into type I and type II pneumocytes. Towards the end of this stage, the fetal lung can support air exchanges largely due to the development of surfactant synthesis and secretion. The alveolar stage begins before birth and lasts into childhood (until 8 years old). In proximal bronchi, pseudostratified ciliated cells and mucous cells are the two major epithelial cell types already present at $\sim 13$ weeks of gestation. Goblet cells express mucin markers (MUC5B and MUC5AC) and release mucous granules into the airways [25].

Concerning epithelial cell lineages in the lung, some transcription factors required for early lung development appear to function not by controlling the behaviour and phenotype of distal progenitors, but

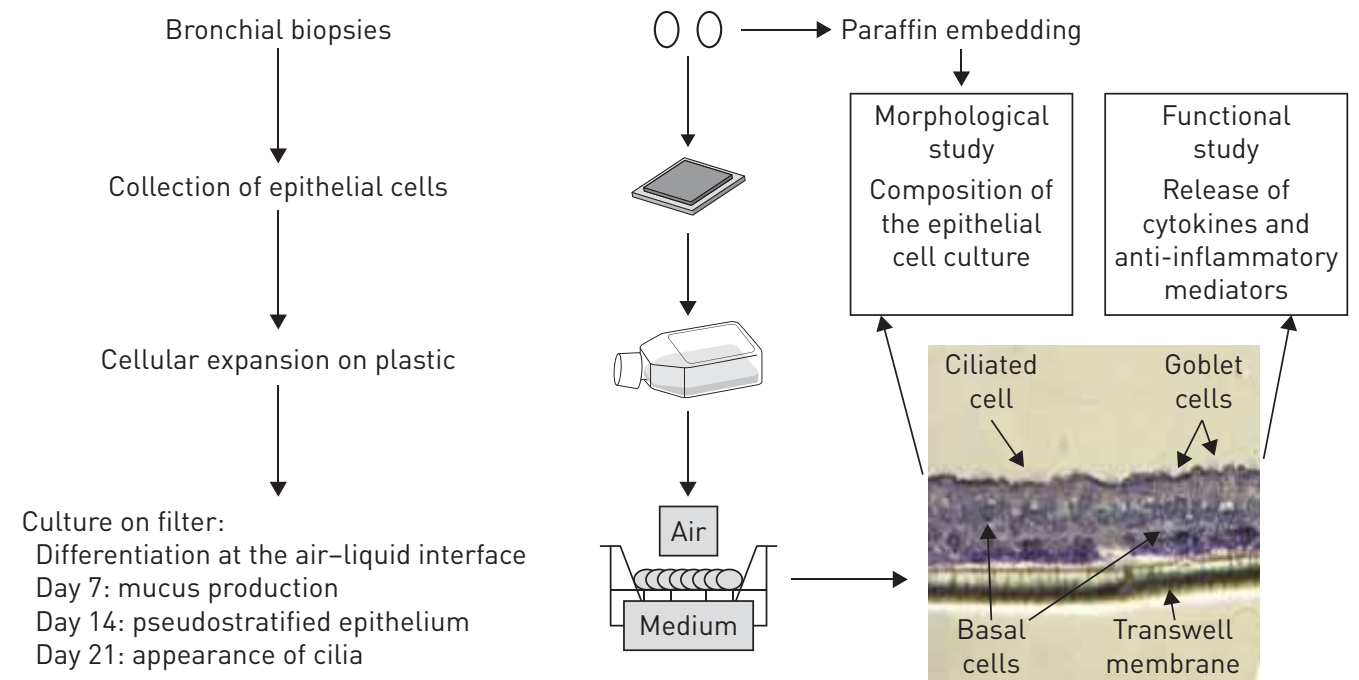

FIGURE 2 Schematic of the differentiation protocol to generate mature airway epithelium using an air-liquid interface. Haematoxylin staining shows cilia on some cells. 
by globally regulating whole transcriptional programmes in epithelial cells of the respiratory system. Among these global regulators are families of transcriptional factors including Gata6, Nkx2-1 (Ttf-1), and Foxa1/2 [26]. Nkx2-1 is initially expressed proximally and distally and becomes restricted at later stages to the distal airway epithelium. At the pseudoglandular stage, the cells in the tips of the buds constitute a pool of highly proliferative multipotent progenitor cells. These progenitor cells self-renew and generate descendants that populate conducting airways. The progenitor cells are maintained by multiple factors and persistent to the canalicular stage where they generate cells that populate the future alveoli. Wnt and Notch signalling regulates the production of bronchiolar cells and then alveolar cells. Putative proximal airway progenitors express Sox2. Notch signalling induces secretory cell or ciliated cell lineages. Similar to the bronchioles, there is no direct evidence that a common epithelial progenitor exists.

Embryological lung mesenchymal and epithelial cells communicate through autocrine and paracrine factors, as demonstrated by the effects of added growth factors on cultured embryonic lung growth. Among biochemical factors, fibroblast growth factor 10 is one of the most studied and controls epithelial differentiation [19]. Epithelial morphogenesis occurs interdependently with vascular development. The epithelium secretes vascular endothelial growth factor, which is essential to develop mature capillary networks. In the same way, the endothelium probably signals back to coordinate epithelial morphogenesis [25].

Besides growth and transcription factors, microRNAs (miRNAs) also participate in lung growth. miRNAs are small non-coding RNAs that function in RNA silencing and post-transcriptional regulation of gene expression. A specific miRNA (miR-17) has been highlighted in lung epithelial cell development [27]. The miR-17 family maintains homeostasis of epithelial structures within the embryonic lung during branching morphogenesis. In addition, miR-449 has been identified as an evolutionarily conserved key regulator of multiciliogenesis, promoting centriole multiplication and contibuting to differentiation of multiciliated cells [28].

Epithelial signalling, gene expression and function can be disrupted during gestation. For example, active maternal smoking during pregnancy has been shown to increase the risk of asthma and chronic obstructive pulmonary disease [29]. Indeed, the bronchial epithelium expresses nicotinic receptors and prenatal exposure to nicotine in vivo has been shown to upregulate mucin secretion in an in vitro model of macaque bronchial epithelium (newborn to 1 year old animals) [30].

\section{Bronchial epithelium in children \\ A physical barrier with chemotactic properties: epithelial cells, junctions and the reticular basement membrane}

Physical barrier function corresponds to the cells themselves and to cellular junctions. At the proximal level of the lower airways, the bronchial epithelium is pseudostratified, prismatic and ciliated, and separated from the underlying submucosa by a thin RBM that is mainly composed of collagen IV. Several epithelial cell types constitute the real tissue: basal cells, ciliated cells and secretory cells (goblet cells). Ciliated cells beat together and are a first step of innate immunity to clean up and keep the liquid layer surrounding the epithelial surface clean. Ciliary beat frequency is regulated by cytokines; in particular, IL-13 is known to play a central role in the regulation of allergic inflammation and to contribute to mucociliary differentiation [17].

Intercellular junctions, including tight junctions, adherent junctions and desmosomes, are the main components the physical barrier. Tight junctions are located at the most apical side of the cell layer, forming the closest site of contact between neighbouring cells and regulating the macromolecular and ionic permeability and polarity of the epithelial barrier. These structures are dynamic, e.g. during leukocyte transmigration, epithelial cells maintain their barrier properties while permitting neutrophils or eosinophils to pass through the para-cellular spaces.

In asthmatic children, the physical barrier is affected by epithelial loss. The percentage of epithelial loss was increased in children with asthma when compared with control subjects. Epithelial loss from atopic non-asthmatic children was comparable to control subjects [31]. This is an important finding since epithelial loss has been related to the biopsy procedure itself. There is some evidence, however, that the epithelium is truly fragile in asthma and that this epithelial shedding may participate in the loss of the physical barrier allowing the penetration of noxious agents [31]. The percentage of epithelial loss was similar in asthmatic children younger or older than 6 years [31]. These pathological changes, while not present at birth, are true early events in the natural history of asthma, as they are seen in the preschool period when both the respiratory and the immune systems are completing their development [31].

A damaged epithelium may trigger events leading to airway remodelling by releasing pro-mitotic and fibrogenic growth factors in excess. These factors may promote smooth muscle proliferation, angiogenesis and 
increased collagen deposition, resulting in so-called RBM thickening [31]. These changes have been widely assessed in adults with asthma and on some occasions in children using analysis of endobronchial biopsies.

The role of changes in the sub-epithelial compartment is not completely understood. It is not an increase in the real basement membrane but the apposition of various components of the extracellular matrix including collagens, fibronectins and laminins. This increased sub-epithelial layer might be protective in asthma, by increasing airway stiffness preventing excessive airway bronchoconstriction [32]. However, in adults the increased thickness of this layer has been associated with asthma severity and is a predictor of poor short-term steroid response [33]. Children with asthma or with allergy without asthma have an increase in "reticular basement membrane thickness" as compared with "healthy children" [31, 34]. In children, RBM thickness is not associated with bronchodilator responsiveness [35]. The thickness of this sub-epithelial layer is increased in children ( $>6$ years old) with asthma as compared with younger ones [31]. RBM thickness is not significantly different between severe asthmatic children with a persistent obstructive pattern and severe asthmatic children with a normal forced expiratory volume in $1 \mathrm{~s}$ [18]. A recent study found that increasing RBM thickness is already present in very young children with asthma risk factors before an established asthma diagnosis [36] strengthening the notion that remodelling may start at a very early age even before the clinical starting point of the disease.

Activation of the bronchial epithelium may promote angiogenesis; the number of vessels and the percentage of area occupied by vessels were increased in children with asthma when compared with normal children [31]. However, by releasing various chemokines such as IL-5, IL-8 and eotaxins, bronchial epithelial cells may attract inflammatory cells, mainly eosinophils. Cytokines may enhance the attraction, activation and survival of these inflammatory cells within the submucosa and promote their migration through the epithelium into the bronchial lumen. In the bronchial submucosa, if the number of eosinophils is increased in endobronchial biopsies [31] and in the BAL fluid of asthmatic children [34, 37], there is no significant correlation between tissue and BAL eosinophils indicating a compartmentalisation of the eosinophils traffic.

Eosinophilic inflammation is not always a feature of asthma in childhood, it was present in only one out of 10 children with moderate asthma in one study [38], and no difference was observed between asthmatic and healthy subjects in another study [39]. However, the role of anti-inflammatory treatments is questionable in those studies. Furthermore, intra-epithelial eosinophils are significantly more frequent in children with persistent symptoms [40], as is the case in adults [41]. The same observation is true for intra-epithelial neutrophils, which are more frequently found in asthmatic children with uncontrolled asthma than in children with controlled disease [41].

Asthmatic bronchial epithelial cell cultures contain higher number of mucus secreting goblet cells compared with non-asthmatic bronchial epithelial cell cultures [42].

The physical barrier of the bronchial epithelium is reproduced in air-liquid interface epithelial cultures, where cohesion is analysed by using specific transepithelial electrical resistance (TEER) measures. TEER represents a marker of redifferentiation of the epithelial cells across the cell culture. There are some data from adults [43-46] showing lower TEER in asthmatic epithelial cultures, but fewer data are available in children. One study, using cultures derived from bronchial brushings, found no significant difference in TEER between asthmatic and non-asthmatic children hemokine gene expression ans laeoinflammatory transcription factors (NF-kB, AP-1 and STAT1/2) chemokine gene expression ans lae [36]. Epithelial integrity can be investigated by performing wound repair experiments. Bronchial epithelial cells from asthmatic children lack the ability to successfully repair mechanically induced wounds [47]. A defect in fibronectin was found to be the potential link to explain this abnormal repair process in asthma.

In the air-liquid interface model, mucociliary clearance can be analysed by measuring ciliary beat frequency and functional imaging of the ciliary layer. In vitro, IL-13 stimulation drives epithelial cells from normal children towards an asthmatic phenotype and worsens the asthmatic phenotype in cells from asthmatic children with goblet cell hyperplasia and decreases numbers of ciliated cells [17]. Morphological features of cells from bronchial biopsies in children are summarised in table 2.

\section{A chemical barrier with host defence properties: mucus, defensins and lysozyme}

Mucous secretion by goblet cells constitutes a major function of the bronchial epithelium to get rid of noxious agents. Apart from mucins, secretions can contain antimicrobial molecules, such as $\beta$-defensins (small proteins) or larger proteins (e.g. lysozyme or lactoferrin) that contribute to nonspecific innate defence.

Mucus, a gel mostly composed of liquid but with the properties of a solid, contains $97 \%$ water and $3 \%$ solids (30\% are mucins, $70 \%$ are non-mucin proteins, salt, lipids and cellular debris) [52]. Goblet cells express mucin markers, release mucus granules that reduce drying, and through ciliary-driven cephalad mucus flow clean the airway. Mucins can be divided into those anchored in the plasma membrane and 
TABLE 2 Bronchial epithelial morphological features of cells obtained from bronchial biopsies in children

Non-asthmatic children

80 (IQR: 0-100)

Median epithelial integrity \%

Epithelial thickness

Tight junction

Reticular basement membrane thickness
No data

$2.7(2.0-3.8) \mu \mathrm{m}$ [31]

$4.2(3.3-4.9) \mu \mathrm{m}[34]$

$4.68 \pm 1.24 \mu \mathrm{m}[49]$

2.6 (IQR: 2.4-3.5) $\mu \mathrm{m}[50]$

$4.4(3.2-6.3) \mu \mathrm{m}[51]$
Severe asthmatic children

45 (IQR: 15-100) [31]

62 (IQR: 30-85) [48]

No data

No data

$4.1(2.5-5.3) \mu \mathrm{m}[31]$

$6(4.5-9.5) \mu \mathrm{m}[34]$

7.2 (IQR: 4.9-8.2) $\mu \mathrm{m}[40]$

$5.21 \pm 1.10 \mu \mathrm{m}[49]$

6.4 (IQR: 5.7-7.8) $\mu \mathrm{m}$ [50]

$>6$ years old: 6.8 (IQR: 6-8.4) $\mu \mathrm{m}$ [48],

or $8.2(5.4-11.1) \mu \mathrm{m}[51]$

$<6$ years old: $4.1(2.5-5.3) \mu \mathrm{m}$

No significant difference between severe asthmatic

children with or without a persistent obstructive pattern

(median (IQR) 6.7 (5.7-9.6) $\mu \mathrm{m}$ and 7.6 (6.1-8.7) $\mu \mathrm{m}$, respectively) [18]

Data are presented as median (range) or mean \pm SD, unless otherwise stated. IQR: interquartile range.

those that are secreted. MUC5B is the principal mucin produced and secreted in the small airways under healthy conditions. MUC5AC may serve little or no important function in healthy airways, but is upregulated during airway inflammation as in asthma [53].

Human $\beta$-defensins (hBD) are small cationic peptides that play an important role in host defence against microbial pathogens in the airway epithelium. There are six $\beta$-defensins identified in humans (hBD1-6). Defensins can be chemotactic for dendritic cells and stimulate mast cells. For example, hBD2 can activate dendritic cells via binding to toll-like receptor (TLR)4 [54]. Although hBD5 and hBD6 have demonstrated antimicrobial activities, they are not expressed in the respiratory epithelium. hBD1 is constitutively expressed in the epithelium, whereas hBD2, hBD3 and hBD4 can be induced by a variety of bacterial, fungal and viral pathogens. hBDs can suppress viral replication by interfering with T-cells, monocytes and immature dendritic cells by inducing cytokine production by epithelial cells and/or by directly binding to certain viruses [55].

In the respiratory tract, lysozyme and lactoferrin are the most abundant antimicrobial proteins. Both proteins have proven antibacterial properties, but act with various mechanisms. Lysozyme is effective against Gram-positive pathogens [56]. Levels of lysozyme produced by epithelial cells are well correlated with clearance of invading pathogens. Lactoferrin chelates iron away from bacteria, but also has direct antimicrobial properties. Lactoferrin works with lysozyme to kill Gram-negative pathogens by disrupting their membrane to expose susceptible peptidoglycans [57]. $\beta$-defensins are not usually detected in healthy BAL samples [57]. There is evidence that airway defensin levels increase during infections with viruses associated with asthma exacerbations [58]. The concentration of immunoglobulins, lactoferrin and lysozyme were compared in bronchial secretions obtained from children with various chronic lung diseases. The IgG, lactoferrin and lysozyme but not secretory IgA concentrations were shown to be increased during chronic inflammatory responses [59]. The mucin secretion (MUC5AC protein) measured in air-liquid interface culture supernatants obtained from children with and without asthma did not differ at rest [36]. Rhinovirus infection of bronchial epithelial cells leads to an increase in hBD-2 and hBD-3 mRNA expression, which may play a role in common cold and virus-associated exacerbation of asthma [60].

\section{Immunomodulatory mediators}

Airway epithelium is able to release immunostimulatory and immunomodulatory mediators such as cytokines and growth factors. CXCL8/IL-8 recruits neutrophils, CXCL10/IP-10 recruits lymphocytes and CXCL5/RANTES recruits eosinophils and participates in airway responsiveness and airway remodelling. However, airway epithelium also initiates antiviral immune responses highlighting the delicate balance that exists between harmful and protective influences in the asthmatic airway [61]. Interferon (IFN) $\gamma$ is involved in modulating the local inflammatory response [55]. Transforming growth factor (TGF)- $\beta 1$ is a cytokine that can exert both profibrotic and anti-inflammatory activities. 
IFN- $\gamma$ levels in BAL were significantly higher in asthmatic children with few symptoms than in asthmatic children with persistent symptoms. In adults, levels of T-helper cell (Th)2-type cytokines (IL-4 and IL-5) were increased while in children levels were similar in BAL [55].

Asthmatic bronchial epithelial cells constitutively produced greater amounts of IL-6, prostaglandin E2 and epidermal growth factor (EGF) than non-asthmatic bronchial epithelial cells, and similar levels of the pro-inflammatory mediators IL-1 $\beta$, soluble intercellular adhesion molecule (ICAM)-1 and IL-8 [15]. By contrast, the expression of TGF- $\beta 1$ was decreased in children with asthma compared with controls [15]. These findings could suggest that TGF- $\beta 1$ signalling may be downregulated in childhood asthma and may be unable to exert its anti-inflammatory or profibrotic activity. However, a recent study compared RBM thickness and the number of TGF- $\beta 1$ positive epithelial cells in bronchial biopsies from children with asthma and other respiratory diseases [50]. The number of TGF- $\beta 1$ positive epithelial cells was higher in asthma subjects than in controls and was correlated with RBM thickness. The production of TGF- $\beta 1$ by activated epithelial cells might thus be an essential step in the initiation of structural changes in bronchi. Indeed, changes to the epithelial basement membrane and deposition of extracellular matrix components in the lamina reticularis lead to pseudo-thickening of the basement membrane, a common feature of airway remodelling. Interaction between bronchial epithelial cells and fibroblasts is known as the epithelial-mesenchymal trophic unit [62]. Bronchial epithelial cells release EGF and fibroblasts produce TGF- $\beta$ to promote synthesis of extracellular matrix components. In the normal state, the RBM is thin and there are few fibroblasts. While in the triggered state, bronchial epithelial cells can produce cytokines and growth factors such as TGF- $\beta$ and epithelial tight junctions are disrupted by proteolytic enzymes or cytokines. TGF- $\beta$ production activates the underlying fibroblasts to differentiate into myofibroblasts that synthesise more collagen and extracellular matrix components. There is also some evidence for epithelialmesenchymal transition, a process whereby epithelial cells acquire characteristics of fibroblasts and downregulate expression of E-cadherin [63].

Airway epithelial cells from asthmatic children differentially express pro-remodelling factors such as periostin. Periostin is a secreted matricellular protein with a key role in amplification and in persistence of chronic inflammation in allergic diseases. Periostin may contribute to asthma pathobiology, including sub-epithelial fibrosis, airway hyperresponsiveness, eosinophil recruitment and mucus production, and thus be a modulator of disease progression [64]. For these reasons, serum periostin could be considered as a systemic biomarker [65]. Periostin is induced by IL-4 and IL-13 in bronchial epithelial cells and lung fibroblasts, and its expression is correlated with RBM thickness. Expression of periostin was significantly higher in both bronchial and nasal epithelial cells from children with asthma than in cells from atopic or healthy children [14]. However, we should also remember that periostin is not specific to asthma or the airway epithelium [64].

\section{Innate immune responses}

Innate immune responses are crucial in asthma pathogenesis. IL-33, IL-25 and thymic stromal lymphopoietin (TSLP) are secreted by the epithelium in response to activation of specific pattern-recognition receptors (TLR3 or TLR5). Tissue damage due to physical stress or infection leads to the release of IL-33 from epithelial cells. IL-33 can induce T-helper cell activation, cytokine production (IL-4, IL-5 and IL-6) and can promote neutrophil migration [66]. Plasma IL-25 levels correlated with epithelial IL-25 expression, airway eosinophilia and beneficial responses to inhaled corticosteroids [67]. This must be studied in asthmatic children and IL-25 could provide a biomarker for Th2 disease. TSLP is a cytokine secreted by the airway epithelium in response to respiratory viruses and is known to promote allergic Th2 responses in asthma. Bronchial epithelium from asthmatic adults produces more TSLP compared with healthy controls when stimulated by double-stranded RNA [68]. However, there is no data in children except for a clinical study that showed increased TSLP in nasal secretions during rhinovirus-induced asthma exacerbations [69].

The innate cytokine IL-33 is of particular interest. IL-33 is expressed in the epithelium of adults with severe asthma. This cytokine promotes a specific feature of airway remodelling, increased RBM thickness, in severe asthmatic children [66]. It seems to be a novel therapeutic target.

Findings obtained from in vitro studies in bronchial epithelial cells are summarised in table 3.

\section{Why should bronchial epithelium in asthmatic children be studied?}

Severe asthma represents a spectrum of disease that remains difficult to control and new therapeutics must be found. It is clear that the epithelium is abnormal and predisposes the individual with asthma towards local allergen sensitisation and the injurious effects of respiratory viruses and air pollutants. A good understanding of the epithelium at baseline and after stimulation is important to find novel therapeutics. 
TABLE 3 Findings obtained in air-liquid interface models from asthmatic and non-asthmatic bronchial cells at the baseline or under stimulation

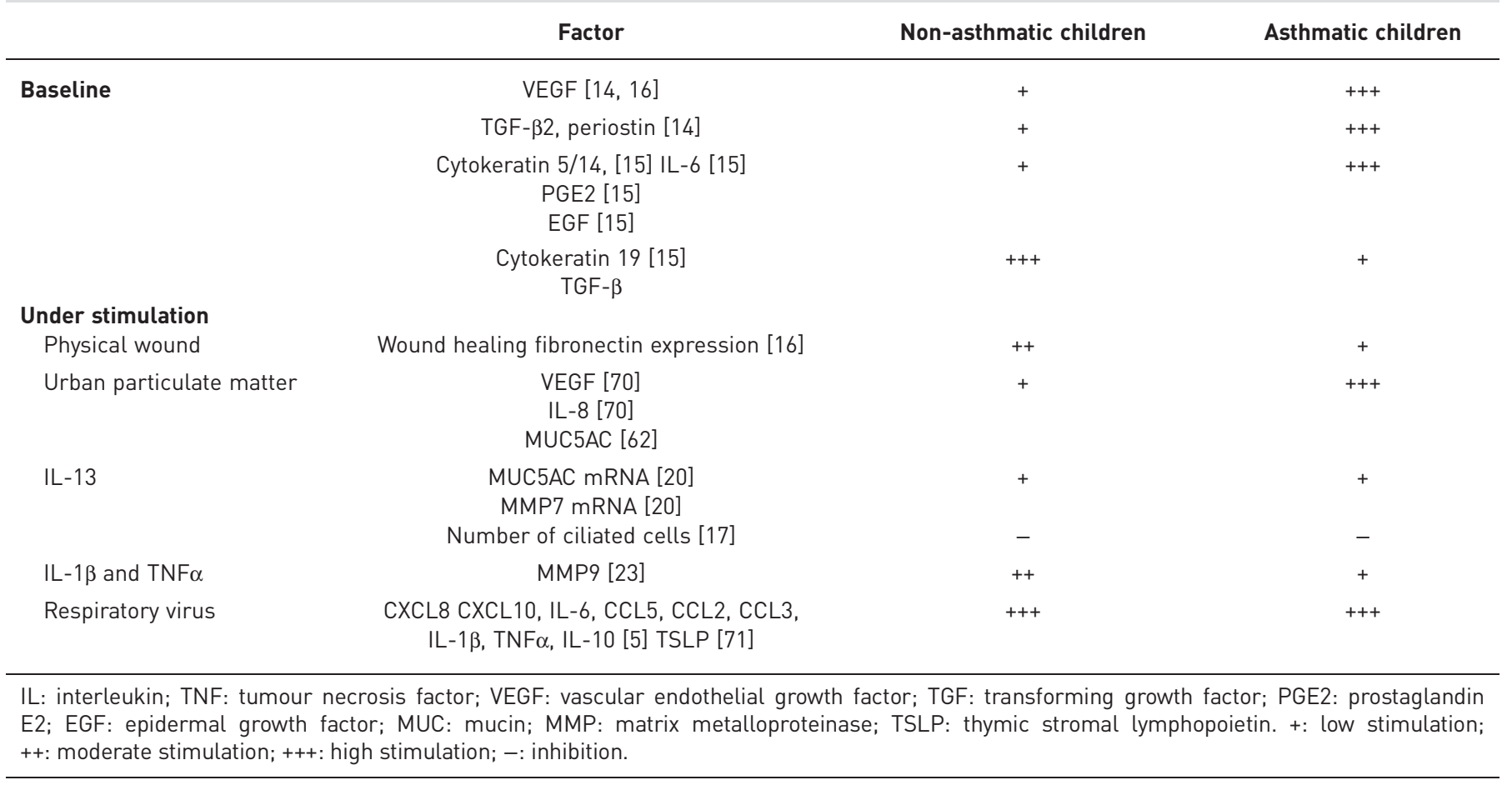

In vitro models allow different types of stimulation by allergens, irritants and infectious agents to be studied and the effects of therapeutics to be tested.

Therapeutic targets in asthmatic adults were discussed in a previous review [72]. Numerous biological therapies have been developed targeting the different biological steps involved in this inflammatory disease. Some well-known targets belong to Th2 pathway such as anti-IgE, IL-5, IL-13, IL-4 and IL-9. Currently, anti-IgE and anti-IL-5 therapies are the only biological therapies available for asthma. A monoclonal anti-IgE antibody (omalizumab) has demonstrated clinical efficacy in patients with allergic asthma. A substantial proportion of severe asthmatics reduced the original bronchial RBM thickness and level of eosinophil infiltration after 1-year of treatment with anti-IgE, thus emphasising the possible role of omalizumab in affecting airway remodelling in severe persistent allergic asthma [73]. The effect of anti-IgE on bronchial epithelial cells was poorly investigated. A single in vitro study showed inhibition of expression and production of pro-inflammatory cytokines [74]. However, anti-IgE effects on airway remodelling in asthma are not completely understood. Treating asthmatics with an anti-IL-5 antibody, which specifically decreased airway eosinophil numbers, significantly reduced the expression of some RBM molecules when compared with placebo [75], but the specific effect on the epithelium is unknown. The role of viruses in the pathogenesis of asthma is widely studied in children and drugs targeting anti-TSLP, IL-25 and IL-33 must be developed. Similarly, viral inhibitors targeting invasion or replication must be developed, e.g. ICAM-1, which acts as natural binding site for human rhinovirus, is being studied as a drug target [76].

\section{Conclusion}

The bronchial epithelium is a key player in health and diseases. Acute and chronic inflammatory disorders are major healthcare problems in childhood. They require constant effort towards improving treatment and prevention. The development of the lung is a factor that may interfere with the future and natural history of these chronic airway disorders. As children are not small adults, specific research efforts should be devoted to better understand the role of the bronchial epithelium in childhood asthma. We should develop models using real epithelium obtained through less invasive methods. The key to promoting prevention at any stage of lung development will be the analysis of responses to microorganisms, allergens and pollutants. The ultimate goals are to prevent future risks of exacerbations, low lung function and the persistence of bronchial hyperresponsiveness. 


\section{References}

1 Global Initiative for Asthma. 2015 GINA Report, Global Strategy for Asthma Management and Prevention. www. ginasthma.org/ Date last accessed: August 11, 2015.

2 Holgate ST. The sentinel role of the airway epithelium in asthma pathogenesis. Immunol Rev 2011; 242: 205-219.

3 Benayoun L, Druilhe A, Dombret M-C, et al. Airway structural alterations selectively associated with severe asthma. Am J Respir Crit Care Med 2003; 167: 1360-1368.

4 Covar RA, Spahn JD, Murphy JR, et al. Progression of asthma measured by lung function in the childhood asthma management program. Am J Respir Crit Care Med 2004; 170: 234-241.

5 Hallstrand TS, Hackett TL, Altemeier WA, et al. Airway epithelial regulation of pulmonary immune homeostasis and inflammation. Clin Immunol 2014; 151: 1-15.

6 Hirota JA, Hackett T-L, Inman MD, et al. Modeling asthma in mice: what have we learned about the airway epithelium? Am J Respir Cell Mol Biol 2011; 44: 431-438.

7 Kumar RK, Foster PS. Are mouse models of asthma appropriate for investigating the pathogenesis of airway hyper-responsiveness?. Front Physiol 2012; 3: 312.

8 Plopper CG, Hyde DM. The non-human primate as a model for studying COPD and asthma. Pulm Pharmaco Ther 2008; 21: 755-766.

9 Bullone M, Lavoie J-P. Asthma "of horses and men" - how can equine heaves help us better understand human asthma immunopathology and its functional consequences? Mol Immunol 2015; 66: 97-105.

10 Hackett T-L, Singhera GK, Shaheen F, et al. Intrinsic phenotypic differences of asthmatic epithelium and its inflammatory responses to respiratory syncytial virus and air pollution. Am J Respir Cell Mol Biol 2011; 45: 1090-1100.

11 McNamara PS, Kicic A, Sutanto EN, et al. Comparison of techniques for obtaining lower airway epithelial cells from children. Eur Respir J 2008; 32: 763-768.

12 Hackett T-L, Shaheen F, Johnson A, et al. Characterization of side population cells from human airway epithelium. Stem Cells 2008; 26: 2576-2585.

13 Hackett T-L, Warner SM, Stefanowicz D, et al. Induction of epithelial-mesenchymal transition in primary airway epithelial cells from patients with asthma by transforming growth factor- $\beta 1$. Am J Respir Crit Care Med 2009; 180: $122-133$.

14 Lopez-Guisa JM, Powers C, File D, et al. Airway epithelial cells from asthmatic children differentially express proremodeling factors. J Allergy Clin Immunol 2012; 129: 990-997.

15 Kicic A, Sutanto EN, Stevens PT, et al. Intrinsic biochemical and functional differences in bronchial epithelial cells of children with asthma. Am J Respir Crit Care Med 2006; 174: 1110-1118.

16 Kicic A, Hallstrand TS, Sutanto EN, et al. Decreased fibronectin production significantly contributes to dysregulated repair of asthmatic epithelium. Am J Respir Crit Care Med 2010; 181: 889-898.

17 Thavagnanam S, Parker JC, McBrien ME, et al. Effects of IL-13 on mucociliary differentiation of pediatric asthmatic bronchial epithelial cells. Pediatr Res 2011; 69: 95-100.

18 Tillie-Leblond I, de Blic J, Jaubert F, et al. Airway remodeling is correlated with obstruction in children with severe asthma. Allergy 2008; 63: 533-541.

19 Sakiyama J-I, Yamagishi A, Kuroiwa A. Tbx4-Fgf10 system controls lung bud formation during chicken embryonic development. Development 2003; 130: 1225-1234.

20 Martin N, Ruddick A, Arthur GK, et al. Primary human airway epithelial cell-dependent inhibition of human lung mast cell degranulation. PLoS One 2012; 7: e43545.

21 Reeves SR, Kolstad T, Lien T-Y, et al. Fibroblast-myofibroblast transition is differentially regulated by bronchial epithelial cells from asthmatic children. Respir Res 2015; 16: 21.

22 Kasper JY, Hermanns MI, Unger RE, et al. A responsive human triple-culture model of the air-blood barrier: incorporation of different macrophage phenotypes. J Tissue Eng Regen Med 2015 [in press; DOI: 10.1002/term.2032].

23 McDougall CM, Blaylock MG, Douglas JG, et al. Nasal epithelial cells as surrogates for bronchial epithelial cells in airway inflammation studies. Am J Respir Cell Mol Biol 2008; 39: 560-568.

24 Pringle EJ, Richardson HB, Miller D, et al. Nasal and bronchial airway epithelial cell mediator release in children. Pediatr Pulmonol 2012; 47: 1215-1225.

25 Warburton D, El-Hashash A, Carraro G, et al. Lung organogenesis. Curr Top Dev Biol 2010; 90: 73-158.

26 Morrisey EE, Hogan BLM. Preparing for the first breath: genetic and cellular mechanisms in lung development. Dev Cell 2010; 18: 8-23.

27 Carraro G, El-Hashash A, Guidolin D, et al. miR-17 family of microRNAs controls FGF10-mediated embryonic lung epithelial branching morphogenesis through MAPK14 and STAT3 regulation of E-Cadherin distribution. Dev Biol 2009; 333: 238-250.

28 Marcet B, Chevalier B, Luxardi G, et al. Control of vertebrate multiciliogenesis by miR-449 through direct repression of the Delta/Notch pathway. Nat Cell Biol 2011; 13: 693-699.

29 Gilliland FD, Li YF, Peters JM. Effects of maternal smoking during pregnancy and environmental tobacco smoke on asthma and wheezing in children. Am J Respir Crit Care Med 2001; 163: 429-436.

$30 \mathrm{Fu} \mathrm{XW}$, Wood K, Spindel ER. Prenatal nicotine exposure increases GABA signaling and mucin expression in airway epithelium. Am J Respir Cell Mol Biol 2011; 44: 222-229.

31 Barbato A, Turato G, Baraldo S, et al. Epithelial damage and angiogenesis in the airways of children with asthma. Am J Respir Crit Care Med 2006; 174: 975-981.

32 Milanese M, Crimi E, Scordamaglia A, et al. On the functional consequences of bronchial basement membrane thickening. J Appl Physiol (1985) 2001; 91: 1035-1040.

33 Bourdin A, Kleis S, Chakra M, et al. Limited short-term steroid responsiveness is associated with thickening of bronchial basement membrane in severe asthma. Chest 2012; 141: 1504-1511.

34 Barbato A, Turato G, Baraldo S, et al. Airway inflammation in childhood asthma. Am J Respir Crit Care Med 2003; 168: 798-803.

35 Bossley CJ, Fleming L, Gupta A, et al. Pediatric severe asthma is characterized by eosinophilia and remodeling without T(H)2 cytokines. J Allergy Clin Immunol 2012; 129: 974-982.

36 Parker JC, Thavagnanam S, Skibinski G, et al. Chronic IL9 and IL-13 exposure leads to an altered differentiation of ciliated cells in a well-differentiated paediatric bronchial epithelial cell model. PLoS One 2013; 8: e61023. 

 noninvasive tests. Am J Respir Crit Care Med 2006; 174: 1286-1291.

Cokuğraş H, Akçakaya N, Seçkin İ, et al. Ultrastructural examination of bronchial biopsy specimens from children with moderate asthma. Thorax 2001; 56: 25-29.

Payne DN, Adcock IM, Wilson NM, et al. Relationship between exhaled nitric oxide and mucosal eosinophilic inflammation in children with difficult asthma, after treatment with oral prednisolone. Am J Respir Crit Care Med 2001; 164: 1376-1381.

de Blic J, Tillie-Leblond I, Tonnel AB, et al. Difficult asthma in children: an analysis of airway inflammation. J Allergy Clin Immunol 2004; 113: 94-100.

Bousquet J, Chanez P, Lacoste JY, et al. Eosinophilic inflammation in asthma. N Engl J Med 1990; 323: 1033-1039.

Parker J, Sarlang S, Thavagnanam S, et al. A 3-D well-differentiated model of pediatric bronchial epithelium demonstrates unstimulated morphological differences between asthmatic and nonasthmatic cells. Pediatr Res 2010; 67: 17-22.

Xiao C, Puddicombe SM, Field S, et al. Defective epithelial barrier function in asthma. J Allergy Clin Immunol 2011; 128: 549-556.

de Boer WI, Sharma HS, Baelemans SMI, et al. Altered expression of epithelial junctional proteins in atopic asthma: possible role in inflammation. Can J Physiol Pharmacol 2008; 86: 105-112.

Post S, Nawijn MC, Jonker MR, et al. House dust mite-induced calcium signaling instigates epithelial barrier dysfunction and CCL20 production. Allergy 2013; 68: 1117-1125.

Blume C, Swindle EJ, Dennison P, et al. Barrier responses of human bronchial epithelial cells to grass pollen exposure. Eur Respir J 2013; 42: 87-97.

Stevens PT, Kicic A, Sutanto EN, et al. Dysregulated repair in asthmatic paediatric airway epithelial cells: the role of plasminogen activator inhibitor-1. Clin Exp Allergy 2008; 38: 1901-1910.

Lezmi G, Gosset P, Deschildre A, et al. Airway remodeling in preschool children with severe recurrent wheeze. Am J Respir Crit Care Med 2015; 192: 164-171.

van Mastrigt E, Vanlaeken L, Heida F, et al. The clinical utility of reticular basement membrane thickness measurements in asthmatic children. J Asthma 2015; 52: 926-930.

Hoňková L, Uhlík J, Beránková K, et al. Epithelial basement membrane thickening is related to TGF-Beta 1 expression in children with chronic respiratory diseases. Pediatr Allergy Immunol 2014; 25: 593-599.

Payne DNR, Rogers AV, Adelroth E, et al. Early thickening of the reticular basement membrane in children with difficult asthma. Am J Respir Crit Care Med 2003; 167: 78-82.

Fahy JV, Dickey BF. Airway mucus function and dysfunction. N Engl J Med 2010; 363: 2233-2247.

Evans CM, Kim K, Tuvim MJ, et al. Mucus hypersecretion in asthma: causes and effects. Curr Opin Pulm Med 2009; 15: 4-11.

Biragyn A, Ruffini PA, Leifer CA, et al. Toll-like receptor 4-dependent activation of dendritic cells by beta-defensin 2. Science 2002; 298: 1025-1029.

Vareille M, Kieninger E, Edwards MR, et al. The airway epithelium: soldier in the fight against respiratory viruses. Clin Microbiol Rev 2011; 24: 210-229.

Travis SM, Conway BA, Zabner J, et al. Activity of abundant antimicrobials of the human airway. Am J Respir Cell Mol Biol 1999; 20: 872-879.

Parker D, Prince A. Innate immunity in the respiratory epithelium. Am J Respir Cell Mol Biol 2011; 45: 189-201.

Proud D. The role of defensins in virus-induced asthma. Curr Allergy Asthma Rep 2006; 6: 81-85.

Zebrak J, Herman T, Werys R, et al. Proteins in bronchial secretion of children with chronic pulmonary diseases. II. Relation to bronchoscopic and bronchographic examination. Scand J Respir Dis 1979; 60: 69-75.

Duits LA, Nibbering PH, van Strijen E, et al. Rhinovirus increases human $\beta$-defensin-2 and -3 mRNA expression in cultured bronchial epithelial cells. FEMS Immunol Med Microbiol 2003; 38: 59-64.

Jackson DJ, Johnston SL. The role of viruses in acute exacerbations of asthma. J Allergy Clin Immunol 2010; 125: 1178-1187.

Holgate ST, Davies DE, Lackie PM, et al. Epithelial-mesenchymal interactions in the pathogenesis of asthma. J Allergy Clin Immunol 2000; 105: 193-204.

63 Lambrecht BN, Hammad H. The airway epithelium in asthma. Nat Med 2012; 18: 684-692.

Izuhara K, Conway SJ, Moore BB, et al. Roles of periostin in respiratory disorders. Am J Respir Crit Care Med 2016; 193: 949-956.

Chiappori A, De Ferrari L, Folli C, et al. Biomarkers and severe asthma: a critical appraisal. Clin Mol Allergy 2015; 13: 20.

Da la Fuente M, MacDonald TT, Hermoso MA. The IL-33/ST2 axis: role in health and disease. Cytokine Growth Factor Rev 2015; 26: 615-623.

Cheng D, Xue Z, Yi L, et al. Epithelial interleukin-25 is a key mediator in Th2-high, corticosteroid-responsive asthma. Am J Respir Crit Care Med 2014; 190: 639-648.

Uller L, Leino M, Bedke N, et al. Double-stranded RNA induces disproportionate expression of thymic stromal lymphopoietin versus interferon-beta in bronchial epithelial cells from donors with asthma. Thorax 2010; 65: 626-632.

9 Nino G, Huseni S, Perez GF, et al. Directional secretory response of double stranded RNA-induced thymic stromal lymphopoetin (TSLP) and CCL11/eotaxin-1 in human asthmatic airways. PLoS One 2014; 9: e115398.

Iwanaga K, Elliott MS, Vedal S, et al. Urban particulate matter induces pro-remodeling factors by airway epithelial cells from healthy and asthmatic children. Inhal Toxicol 2013; 25: 653-660.

1 Lee H-C, Headley MB, Loo Y-M, et al. Thymic stromal lymphopoietin is induced by respiratory syncytial virus-infected airway epithelial cells and promotes a type 2 response to infection. J Allergy Clin Immunol 2012; 130: $1187-1196$

Gras D, Chanez P, Vachier I, et al. Bronchial epithelium as a target for innovative treatments in asthma. Pharmacol Ther 2013; 140: 290-305.

Riccio AM, Dal Negro RW, Micheletto C, et al. Omalizumab modulates bronchial reticular basement membrane thickness and eosinophil infiltration in severe persistent allergic asthma patients. Int J Immunopathol Pharmacol 2012; 25: 475-484. 
74 Huang Y-C, Leyko B, Frieri M. Effects of omalizumab and budesonide on markers of inflammation in human bronchial epithelial cells. Ann Allergy Asthma Immunol 2005; 95: 443-451.

75 Flood-Page P, Menzies-Gow A, Phipps S, et al. Anti-IL-5 treatment reduces deposition of ECM proteins in the bronchial subepithelial basement membrane of mild atopic asthmatics. J Clin Invest 2003; 112: 1029-1036.

76 Traub S, Nikonova A, Carruthers A, et al. An anti-human ICAM-1 antibody inhibits rhinovirus-induced exacerbations of lung inflammation. PLoS Pathog 2013; 9: e1003520. 